\title{
Abomasal nematode parasites in goats slaughtered in Mekelle town, northern Ethiopia
}

\author{
Kassaye Berhe and Kassaye Aragaw* \\ Hawassa University, School of Veterinary Medicine, P.O. Box 05, Hawassa, Ethiopia \\ "Corresponding author. Tel.: +251924456196; E-mail address: kassaye.a@gmail.com (K. Aragaw).
}

\begin{abstract}
Infection with abomasal nematodes, especially haemonchosis, is one of the most important problems challenging small ruminant production in the tropics. This study was carried out to identify nematodes infecting the abomasa, and estimate their prevalence and count in goats slaughtered in Mekelle town, northern Ethiopia. A total of 166 abomasa of goats were examined for postmortem differential adult nematode parasites count using standard procedure. Haemonchus spp. and Trichostrogylus axei were recovered from 126 (75.9\%) and 109 (65.7\%) abomasa, respectively. It was noted that $152(91.6 \%)$ goats harbored at least one of the parasites, while $83(50 \%)$ goats were found infected with both parasites. Mean and maximum adult worm counts were 39.2 and 270 and 55.2 and 600 for Haemonchus spp. and T. axei, respectively. Months of the year had significant $(p<0.05)$ effect on prevalence and adult worm count in both species of parasites identified. The adult worm count and prevalence were relatively high in February for Haemonchus spp. and in December for T. axei. The high prevalence of these economically important parasites in goats in the dry season may entail insidious losses they could incur in the productivity of goats in the study area.
\end{abstract}

Keywords: Abomasal nematodes; Ethiopia; Goat; Haemonchus; Trichostrogylus axei

\section{Introduction}

Goats in Ethiopia, with estimated population of about 30.2 million (CSA, 2017), makeup a significant proportion of the country's ruminant livestock inventory. They are integral part of the mixed crop-livestock system commonly practiced in the highlands of the country and the pastoral and agro-pastoral systems of the arid and semi-arid lowlands (Tolera and Abebe, 2007; Legesse et al., 2010; Kebede et al., 2012). Goats considerably contribute to household income and 
nutrition of rural population of Ethiopia, and export earnings of the country (FAO, 2004; Tolera and Abebe, 2007; Legesse et al., 2010).

Infections with gastrointestinal (GI) nematodes remain one of the most prevalent parasitic diseases affecting small ruminants worldwide (Torres-Acosta and Hoste, 2008). They cause considerable economic loss mainly due to insidious production loss in addition to clinical diseases and mortalities they cause (Over et al., 1992). GI nematode parasites, especially haemonchosis, are significant causes of loss of productivity and mortality in small ruminants in Africa (Allonby and Urquhart, 1975; Githigia et al., 2001). Though not substantially supported by studies quantifying losses, researchers have agreed that nematode infections are among the most devastating diseases of small ruminants in Ethiopia with huge economic significance (Asmare et al., 2016).

Surveys conducted in different places in Ethiopia (Abebe and Esayas, 2001; Woldemariam, 2005; Menkir et al., 2007; Aga et al., 2013; Haile et al., 2018) and elsewhere in Africa (Githigia et al., 2001) demonstrated that Haemonchus spp., are generally the most dominant GI nematode parasites in goats. Other commonly reported groups of abomasal parasites in goats in Ethiopia include: Trichostrongylus axei and Ostertagia/Teladorsagia spp. (Abebe and Esayas, 2001; Kumsa and Wossene, 2006; Bitew et al., 2011; Aga et al., 2013; Teshale and Aragaw, 2014).

The development of cost-effective and sustainable control program to helminth infections requires thorough knowledge of the species of parasites present in an area among others (Hansen and Perry, 1994). Therefore, this study was conducted to identify nematodes infecting the abomasa, and estimate their prevalence and intensity of infection in goats slaughtered in Mekelle town in northern Ethiopia.

\section{Materials and Methods}

\section{Study area}

The study was conducted in Mekelle town, the capital of Tigray Region, located about $783 \mathrm{~km}$ north of Addis Ababa. The area lies between $13^{\circ} 32^{\prime}$ and $13^{\circ} 30^{\prime} \mathrm{N}$ latitude and $39^{\circ} 29^{\prime}$ and $39^{\circ} 39^{\prime} \mathrm{E}$ longitude and covers a total area of 3500 hectares in the northern highlands of Ethiopia (Fig. 1). The elevation of the city measures between 2000 and 2270 m.a.s.l. Agro-climate of the area is semi-arid 
with average minimum and maximum temperature of 17.6 and $24.3^{\circ} \mathrm{C}$, respectively and annual rainfall of $700 \mathrm{~mm}$ (TBOANR, 1999; MCPPP, 2007).

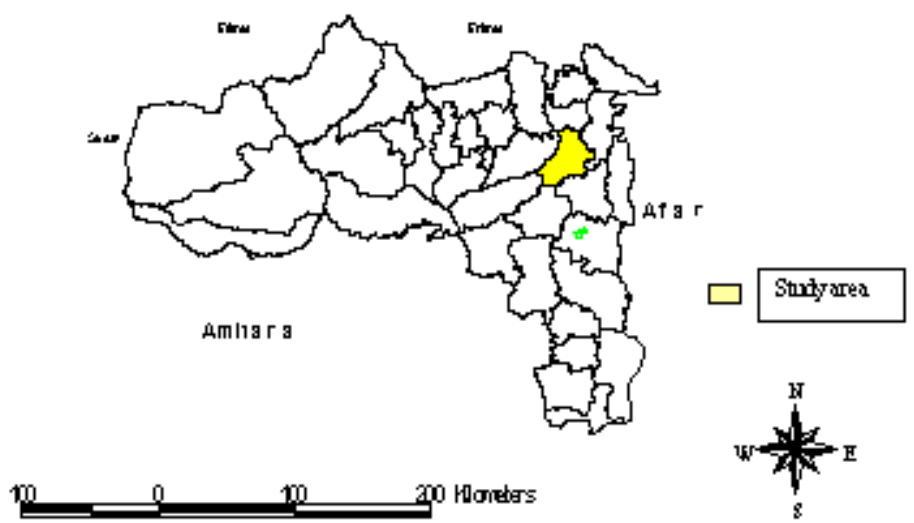

Figure 1. Location of the study in Tigray Regional State, Ethiopia

\section{Study Animals}

Abomasa of 166 local goats slaughtered in different restaurants of Mekelle town were collected for parasitological examination between November 2008 and February 2009. Goats in the area are raised with the traditional extensive system. Goats are supplied to Mekelle market from districts surrounding the town. Goats of both sexes usually aged between 1 and 4 years are slaughtered in the town.

\section{Study design, Sampling and Sample size}

The study was a cross-sectional study involving post-mortem examination of abomasa from slaughtered goats selected using a systematic random sampling technique. The sample size was determined based on $88 \%$ estimated prevalence (Kumsa and Wossene, 2006), 95\% level of confidence, and 5\% absolute precision (Thrusfield, 2005), requiring a minimum sample size of 162 animals. Restaurants slaughtering goats in Mekelle town were identified and those which were willing to cooperate after being briefed about the objectives of the study were included in the study. 


\section{Sample collection, processing, worm identification and count}

Abomasal samples were collected from the restaurants on prearranged visits. The abomasa, after being ligated, were cut at both ends (at omasal and duodenal junctions) to separate from the rest of the digestive tract. They were transported to Mekelle Regional Veterinary Laboratory, Parasitology Department, where the laboratory examination was conducted. Standard procedures were used to recover, identify and count adult worms (MAFF, 1977; Hansen and Perry, 1994). Briefly, the abomasum was opened along the greater curvature, the contents poured into a graduated bucket, and the mucosal surface washed carefully into the bucket paying attention to the folds. The total volume was made to 2 liters from which an aliquot of $200 \mathrm{ml}$ was transferred to graduated beaker while the content was stirred. The aliquot was filtered through a sieve of $250 \mu \mathrm{m}$ apertures and the whole matter remaining on the sieve was re suspended in water. This was repeated until debries that would obscure the detection of the worms were reasonably cleared. Subsamples were placed in petridish and examined under a stereomicroscope. The numbers of worms obtained in the $200 \mathrm{ml}$ aliquot were multiplied by 10 to determine the total number of worms.

Degree of infection for specific parasite species was categorized as described by Hansen and Perry (1994) as light, moderate and heavy with count of 1-500, 501-1,500, >1,500 and 1-1,000, 1,001-10,000, >10,000 for Haemonchus and T. axei, respectively.

\section{Data analysis}

Microsoft Excel was used to store the data and in the analysis of descriptive statistics. Prevalence was calculated as a percentage of goats having at least 1 worm of a certain species of parasite out of a total of goats examined. Comparison of prevalence among months was analyzed using Chi-square test. The worm count data were $\log$ transformed $\left[\log _{10}(\mathrm{EPG}+1)\right]$ and worm count difference between months was analyzed using one-way analysis of variance (ANOVA). STATA version 7 was used for the Chi-square and SPSS version 13 for the ANOVA. 


\section{Results}

\section{Prevalence}

Two species of nematode parasites, namely Haemonchus spp. and Trichostrogylus axei were identified from the abomasa of the study goats. Out of the 166 abomasa of goats examined 126 (75.9\%, 95\% CI: 69.3-82.5) and 109 (65.7\%, 95\% CI: 58.4-73.0) were harboring Haemonchus spp. and T. axei, respectively. The overall prevalence of abomasal parasites was 91.6\% (95\% CI: 87.3-95.8). Eighty-three (50\%, 95\% CI: 35.0-65.0) of the goats had both parasites in their abomasa (Table 1).

Table 1.Prevalence of abomasal parasites in goats slaughtered in Mekelle town, northern Ethiopia $(\mathrm{n}=166)$

\begin{tabular}{lccc}
\hline Parasite species & No. positive & \%Prevalence & 95 \% CI \\
\hline Haemonchus spp. & 126 & 75.9 & 69.3 - \\
& & & 82.5 \\
T. axei & 109 & 65.7 & $58.4-$ \\
& & & 73.0 \\
Haemonchus spp. and T. axei & 83 & 50.0 & $35.0-$ \\
& & & 65.0 \\
At least one parasite & \multirow{2}{*}{152} & 91.6 & $87.3-$ \\
& & & 95.8 \\
\hline
\end{tabular}

Month had significant $(P<0.05)$ effect on prevalence of both species of parasites identified (Table 2). The highest proportion of goats with at least one adult parasite was recorded in February for Haemonchus spp. (100\%) and in December for T. axei (81\%).

\section{Worm burden}

Mean adult parasitic worm count from abomasa of goats slaughtered in Mekelle during the study period is shown in Table 2 . The recorded mean counts (considering all goats examined) were 39.5 and 55.2 for Haemonchus spp. and T.axei, respectively. The corresponding mean $( \pm \mathrm{SE})$ adult worm count for positive goats were $52.1( \pm 4.4)$ and $84.0( \pm 9.8)$.

Significant differences $(P<0.05)$ were observed among months in mean worm count for both Haemonchus spp. and T. axei (Table 2). Relatively highest counts were observed in February for Haemonchus spp. and in December for T. axei. 
The maximum counts recorded were 270 and 600 in December for Haemonchus spp. and T. axei, respectively. Haemonchus spp. has shown relative highest prevalence and mean count in February.

Counts for both parasites in all positive goats observed in the study (maximum count of 270 and 600 adult worms for Haemonchus and T. axei, respectively) revealed light degree of infection.

Table 2. Monthly prevalence and worm burden of abomasal nematodes in goats slaughtered in Mekelle

\begin{tabular}{|c|c|c|c|c|c|c|c|c|c|}
\hline \multirow{2}{*}{$\begin{array}{l}\text { Parasite } \\
\text { species }\end{array}$} & \multirow[t]{2}{*}{ Month } & \multirow{2}{*}{$\begin{array}{l}\text { No. } \\
\text { Examined }\end{array}$} & \multicolumn{4}{|c|}{ Prevalence } & \multicolumn{3}{|c|}{ Worm burden } \\
\hline & & & $\begin{array}{l}\text { No. (\%) } \\
\text { Positive }\end{array}$ & $\begin{array}{l}95 \% \\
\text { CI }\end{array}$ & $x^{2}$ & $\begin{array}{l}P \\
\text { value }\end{array}$ & $\begin{array}{l}\text { Mean } \\
( \pm \text { SE })\end{array}$ & Min & Max \\
\hline \multirow[t]{5}{*}{$\begin{array}{l}\text { Haemonchus } \\
\text { spp. }\end{array}$} & Nov & 24 & 19(79.2) & $\begin{array}{c}62.9- \\
95.4\end{array}$ & 11.8 & 0.008 & $\begin{array}{c}30.8 \\
( \pm 6.4) \mathrm{a}\end{array}$ & 0 & 120 \\
\hline & Dec & 79 & $52(65.8)$ & $\begin{array}{c}55.4- \\
76.3\end{array}$ & & & $\begin{array}{c}29.6 \\
( \pm 5.3) \mathrm{a}\end{array}$ & 0 & 270 \\
\hline & Jan & 42 & $34(81.0)$ & $\begin{array}{l}69.1- \\
92.8\end{array}$ & & & $\begin{array}{c}37.6 \\
( \pm 5.2) \mathrm{a}\end{array}$ & 0 & 130 \\
\hline & Feb & 21 & $21(100)$ & - & & & $\begin{array}{c}90.5 \\
( \pm 13.5) \mathrm{b}\end{array}$ & 20 & 220 \\
\hline & Overall & 166 & $126(75.9)$ & $\begin{array}{l}69.3- \\
82.5\end{array}$ & & & $\begin{array}{c}39.5 \\
( \pm 3.8)\end{array}$ & 0 & 270 \\
\hline \multirow[t]{5}{*}{ T. axei } & Nov & 24 & $5(20.8)$ & $\begin{array}{l}4.6- \\
37.1\end{array}$ & 33.3 & 0.000 & $\begin{array}{c}9.6 \\
( \pm 4.4) \mathrm{a}\end{array}$ & 0 & 80 \\
\hline & Dec & 79 & $64(81.0)$ & $\begin{array}{l}72.4- \\
89.7\end{array}$ & & & $\begin{array}{c}86.7 \\
( \pm 13.6) \mathrm{b}\end{array}$ & 0 & 600 \\
\hline & Jan & 42 & $30(71.4)$ & $\begin{array}{l}57.8- \\
85.1\end{array}$ & & & $\begin{array}{c}39.5 \\
( \pm 6.3) \mathrm{b}, \mathrm{c}\end{array}$ & 0 & 140 \\
\hline & $\mathrm{Feb}$ & 21 & $10(47.6)$ & $\begin{array}{c}26.3- \\
69.0\end{array}$ & & & $\begin{array}{c}26.8 \\
( \pm 5.9) \mathrm{a}, \mathrm{c}\end{array}$ & 0 & 80 \\
\hline & Overall & 166 & $109(65.7)$ & $\begin{array}{c}58.4- \\
73.0\end{array}$ & & & $\begin{array}{c}55.2 \\
( \pm 7.1)\end{array}$ & 0 & 600 \\
\hline
\end{tabular}

\section{Discussion}

Only two genera of nematodes namely Haemonchus and Trichostrogylus were detected in the abomasa of the study goats. This is in agreement with the reports of similar studies in the northern and eastern parts of the country (Abebe and Esayas, 2001; Kumsa and Wossene, 2006; Menkir et al., 2007; Teshale and 
Aragaw, 2014). However, studies in southern Ethiopia (Asha and Wossene, 2007; Thomas et al., 2007; Bitew et al., 2011; Demissie et al., 2013) frequently documented the occurrence of another abomasal nematode parasite namely Teladorsagia (Ostertagia) spp. in addition to the two genera recovered in this study. Ostertagia is known to be especially important in temperate climates and in subtropical regions with winter rainfall (Urquhart et al., 1996).

The high overall prevalence (91.6\%) of abomasal nematodes in goats in Mekelle, revealed by the current study is comparable to 95\% (Abebe and Esayas, 2001) and 90.2\% (Kumsa and Wossene, 2006) prevalence reported from eastern and $87.1 \%$ from southern Ethiopia (Thomas et al., 2007). It was, however, higher compared to $45.2 \%$ (Teshale and Aragaw, 2014) and 61.8\% (Bitew et al., 2011) prevalence reported from northwestern and southern Ethiopia, respectively. Such high prevalence of abomasal helminth parasites in goats suggests existence of favorable environmental conditions for survival and development of nematode larvae to infective stage in the study area. It also suggests that goats, which are normally browsers, may have been forced to graze perhaps due to lack of adequate browsing material in the study area (Le Jambre and Royal, 1976).

The recorded high prevalence of Haemonchus spp. (75.9\%) in our study was in agreement with 76.5\% (Thomas et al., 2007) and 75.2\% (Demissie et al., 2013) prevalence reported from southern Ethiopia. Bitew et al. (2011) from southern Ethiopia (55.9\%) and Teshale and Aragaw (2014) from northwestern Ethiopia (43.5\%) have reported much lower prevalence. Other works however recorded higher prevalence of the parasite in slaughtered goats in Ethiopia (Abebe and Esayas, 2001; Kumsa and Wossene, 2006).

Comparable prevalence of T. axei (64.3\%), to our study (65.7\%), was recorded in eastern Ethiopia by Abebe and Esayas (2001). However, several other studies from different parts of the country recorded lower prevalence of the parasite in slaughtered goats (Kumsa and Wossene, 2006; Thomas et al., 2007; Bitew et al., 2011; Demissie et al., 2013; Teshale and Aragaw, 2014). These differences in prevalence of the parasites among the studies are most likely due to difference in environmental conditions, as they affect the development and survival of the parasites outside and inside the host (Urquhart et al., 1996).

The average worm count observed for both Haemonchus spp. (39.5) and Tricostrongylus axei (55.2) in our study were much lower compared to reports of sev- 
eral similar earlier studies in Ethiopia (Abebe and Esayas, 2001; Menkir et al., 2007; Thomas et al., 2007; Teshale and Aragaw, 2014). This may be explained by difference in agroclimatic conditions among the study areas which affect favorability of the environment for development and survival of the free living stages of the parasites (Urquhart et al., 1996). It may also be partly explained by difference in season of study among the reports. Our study was conducted during the dry season where parasite prevalence and burden are usually low (Bekele et al., 1987; Tembely et al., 1997; Menkir et al., 2007).

In the present study all of the goats harboring adult abomasal parasites were affected by light degree of infection based on the interpretation suggested by Hansen and Perry (1990). In a somewhat different result Kumsa and Wossene (2006) in goats from eastern Ethiopia found a few animals with heavy infection, while majority of the infected goats were with light to moderate degree of infection. The reasons for light degree of infection for both parasites notwithstanding high prevalence need further investigation.

Monthly prevalence and total adult worm burden of the identified abomasal parasites in the study period had shown difference which was relatively highest in February for Haemonchus spp. and in December for T. axei, although there was no change in degree of infection. This difference is difficult to explain as there was no significant rain during the study period in the area. Under Ethiopian highland conditions, moisture appears to have the most important effect on the development and survival of eggs and larvae of nematodes (Haile et al., 2010).

\section{Conclusions}

The present study demonstrated high prevalence of pathologically the most important nematode parasite of ruminants- Haemonchus spp.- along with $T$. axei in goats in the study area, albeit with light degree of infection. The results suggest insidious losses of production in goats in the study area due to helminth parasites.

\section{Acknowledgements}

The authors would like to thank Dr. Girmay W/Selassie, head of Mekelle Regional Veterinary Laboratory for his unreserved help in facilitating the study. Owners of Mekelle restaurants with their butcher men are also appreciated for 
their kindness in provision of samples. Traders of goats in Mekelle, especially Ato Nigus, are gratefully acknowledged for provision of information.

\section{Conflict of Interest}

The authors declare that there is no conflict of interest.

\section{References}

Abebe, W. and Esayas, G., 2001. Survey of ovine and caprine intestinal helminthosis in eastern part of Ethiopia during the dry season of the year. Rev. Med. Vet., 152, 379-384.

Aga, S., Tolossa, Y. and Terefe, G., 2013. Epidemiology of gastrointestinal nematodes of Horro sheep in Western Oromia, Ethiopia. J. Vet. Med. Anim. Health. 5 (10), 296-304.

Allonby, E.W. and Urquhart, G.M., 1975. The epidemiology and pathogenic significance of haemonchosis in a merino flock in east Africa. Vet. Parasitol. 1, 129-143.

Asha, A. and Wossene, A., 2007. Gastrointestinal tract nematodosis of small ruminants in three different agro-ecological zones in southern Ethiopia. Ethiop. Vet. J., 11(1), 83-94.

Asmare, A., Sheferaw, D., Aragaw, K., Abera, M., Sibhat, B., Haile, A., Kiara, H., Szonyi, B., Skjerve, E. and Wieland, B., 2016. Gastrointestinal nematode infection in small ruminants in Ethiopia: A systematic review and meta-analysis. Acta Trop., 160, 68-77.

Bekele, T., Mukasa-Mugerwa, E. and Scholtens R.G., 1987. Seasonal changes in nematode faecal egg counts of sheep in Ethiopia. International Livestock Centre for Africa (ILCA). Bulletin No. 29.

Bitew, M., Yeshitla, A. and Kidist, B., 2011. Abomasal and small intestinal nematodes ruminants slaughtered in different restaurants in Hawassa. Vet. Res., 4 (2), 39-44.

Chaudary, R. F. Khan, U. F. M., and Qayyum, M., 2007. Prevalence of Haemonchus contortus in naturally infected small ruminants grazing in the Potohar area of Pakistan. Pakistan. Vet. J., 27(2), 73-79.

CSA (Central Statistical Agency), 2017. Report on livestock and livestock characteristics (private peasant holdings). Agricultural sample survey 2016/17[2009 e.c.], Volume II Statistical bulletin 585. 
Demissie, T., Tesfaye, D., Fekadu, A. and Asefa, I., 2013. Study on abomasal nematodes of sheep and goats: comparison and characterization of vulvar morphology of Haemonchus in Hawassa, Ethiopia. Afr. J. Agric. Res., 8 (39), 4922-4927.

FAO (Food and Agriculture Organization of the United Nations), 2004. Livestock sector brief: Ethiopia. Livestock information, sector analysis and policy branch (AGAL), FAO, Rome, Italy.

Githigia, S.M., Thamsborg, S.M., Munyua, W.K. and Maingi, N. (2001). Impact of gastrointestinal helminths on production in goats in Kenya. Small Rumin. Res., 42, 21-29.

Haile, A., Gashaw, A., Tolamariam, T., and Tibbo, M., 2010. Epidemiology of nematode parasites of sheep around Jimma, South Western Ethiopia. Trop. Anim. Hlth. Prod., 42(5), 825-831.

Haile, A., Hassen, H, Gatew, H., Getachew, T., Lobo, R. N. B. and Rischkowsky, B., 2018. Investigations into nematode parasites of goats in pastoral and crop livestock systems of Ethiopia. Trop. Anim. Hlth. Prod., 50(3), 643-650.

Hansen, J. and Perry, B., 1994. The Epidemiology and Control of Helminth Parasites of Ruminants, A hand book, International Laboratory for Research on Animal Disease. Nairobi, Kenya. Pp 3-149.

Kebede, T., Haile, A. and Dadi, H., 2012. Smallholder goat breeding and flock management practicesin the central rift valley of Ethiopia. Trop. Anim. Hlth. Prod., 44, 999-1006.

Kumsa, B. and Wossene, A., 2006. Abomasal nematodes of small ruminants of Ogaden region, eastern Ethiopia: Prevalence, Worm burden and species composition. Rev. Med. Vet., 157(12), 27-32.

Legesse, G., Siegmund-Schultze, M., Abebe, G., Valle Zárate, A., 2010. Economic performance of small ruminants in mixed-farming systems of southern Ethiopia. Trop. Anim. Hlth, Prod., 42, 1531-1539.

Le Jambre, L.F. and Royal, W.M., 1976. A comparison of worm burden in grazing Merino sheep and Angora goats. Aust. Vet. J., 52, 181-183.

MAFF (1997): Manual of Veterinary Parasitological Laboratory Techniques. Tech. Bull. No., 18: Her majesty's Stationary office, London 1-5.

MCPPP (2007): Mekelle town Municipality. Mekelle City Plan Preparation Project.

Menkir, M., Uggla, A., Waller, P.J., 2007. Prevalence and seasonal incidence of nematode parasites and fluke infections of sheep and goats in eastern Ethiopia. Trop. Anim. Hlth. Prod., 39, 521-531. 
Over, H. J., Jansen, J. and van Olm, P. W., 1992. Distribution and impact of helminth diseases of livestock in developing countries. FAO Animal Production and Health Paper 96.

TBOANR, 1999. Tigrai Bureau of Agriculture and Natural Resources, Annual Report.

Tembely, S., Lahlou-kassi, A., Rege, J.E.O., Sovani, S., Diedhiou, M.L., Baker, R.L., 1997. The epidemiology of nematode infections in sheep in a cool tropical environment. Vet. Parasitol., 70, 129-141.

Teshale, A. and Aragaw, K., 2014. Abomasal nematodes of small ruminants slaughtered in Bahir Dar town, Northwest Ethiopia. J. Vet. Med. Anim. Health, 6 (10), 257-262.

Thomas, N., Teshale, S., and Bersissa, K. (2007): Abomasal Nematodes of Sheep and Goats Slaughtered in Awassa (Ethiopia): Species Composition, Prevalence and Vulvar Morphology. Helminthologia, 44, 70-75.

Thrusfield, M., 2005. Veterinary Epidemiology. 3rd ed. Blackwell science Ltd, London, pp. 228-246.

Tolera, A. and Abebe, A., 2007. Livestock production in pastoral and agro-pastoral production systems of southern Ethiopia. Livestock Res. Rural Dev., 19(12), 1-13.

Torres-Acosta, J.F.J. and Hoste, H., 2008. Alternative or improved methods to limit gastro-intestinal parasitism in grazing sheep and goats. Small Rumin. Res., 77, $159-173$.

Urquhart, G. M., Armour, J., Duncan, J. L., Dunn, A. M., and Jennings, F. W. (1996): Veterinary Parasitology. $2^{\text {nd }}$ Edition, Black Well Science. PP 3 - 26.

Woldemariam, D.L., 2005. Nematode prevalence, helminth management practices and anthelmintic resistance in small ruminants in the mid-rift valley of Ethiopia. Doctor of Veterinary Science Thesis, University of Pretoria, Department of Veterinary Tropical Diseases, Faculty of Veterinary Science, Republic of South Africa. 